\title{
Economic Efficiency of Smallholder Dairy Farmers in Swaziland: An Application of the Profit Function
}

\author{
B. B. Masuku \\ P. O. Box 710, Piggs Peak, Swaziland \\ M. B. Masuku (Corresponding author) \\ Department of Agricultural Economics and Management \\ P. O. Luyengo, Luyengo. M205, University of Swaziland, Swaziland \\ Tel: 268-7602-6557_E-mail: mbmasuku@uniswa.sz

\begin{abstract}
A. Belete
Department of Agricultural Economics

University of Limpopo, PB X1106, Sovenga 0727, South Africa
\end{abstract}

Received: July 30, 2014 Accepted: August 18, 2014

doi:10.5296/jas.v2i2.6046 URL: http://dx.doi.org/10.5296/jas.v2i2.6046

\begin{abstract}
The purpose of the study was to analyse the economic efficiency of smallholder dairy farmers in Swaziland. Specifically, the study sought to describe the socio-economic characteristics of dairy farmers in Swaziland. The smallholder farmers are classified into: smallholder farmers, medium-scale farmers, and large-scale dairy farmers. The specific objectives of the study were to: estimate the economic efficiency of smallholder dairy farmers in Swaziland; identify factors affecting the economic efficiency of smallholder dairy farmers; and determine the profitability of the smallholder dairy enterprise. This was a descriptive and quantitative survey and the target population was all smallholder dairy farmers registered with the Swaziland Dairy Board $(\mathrm{N}=444)$. A purposive and random sampling techniques was used to select the respondents ( $\mathrm{n}$ = 111). Three methods of data analysis were used, namely; descriptive statistics, econometric analysis (Stochastic Profit Frontier Function) and gross margin analysis. The mean level of Economic Efficiency (EE) for the famers was 79.8\%. The farm's location, pasture size, soil
\end{abstract}


fertility, water availability, the farmer's years of experience in dairy farming, membership to dairy farmers' association and training on dairy farming are factors that influenced the level of $\mathrm{EE}$ for smallholder dairy farmers in Swaziland. The smallholder dairy farmers were economically efficient. The institutional factors, socioeconomic and farm characteristics do affect the level of EE among smallholder dairy farmers. The dairy farming enterprise is a profitable enterprise.

Keywords: Economic Efficiency, Gross Margin, Stochastic Profit Function, Swaziland

\section{Introduction}

Swaziland has a dual land tenure system consisting of Swazi Nation Land (SNL) and Title Deed Land (TDL). The dairy industry in Swaziland is developed and regulated by the Swaziland Dairy Board (SDB). According to T. Mnisi (personal communication, November $14^{\text {th }}, 2013$ ) dairy farmers in Swaziland are divided into three categories namely; smallholder farmers (herd size ranges from 1 - 10 cows), medium-scale farmers (herd size ranges from 11 - 40 cows), and large-scale dairy farmers (herd size is more than 40 cows). There is a high demand for milk and its products in Swaziland. In 2008, the annual demand for milk and milk products was documented to be 56 million litres per year, whereas milk production from the national dairy herd was 8.4 million litres, leaving a shortage of 47.6 million litres (CBS, 2009). In 2009, dairy imports amounted to 44.3 million litres of liquid milk equivalents (LME) (CBS, 2010). During the 2009/2010 financial year, the demand for dairy products became 52 million litres per annum in liquid milk equivalents (LME), while milk production from the national dairy herd was 7.52 million litres per annum. The shortage on the same year was 44.48 million litres. This shortage was covered by imports of dairy products and milk from South Africa. Swaziland imports over E800 million worth of dairy products, consisting of cheese, cream, yoghurt and others, annually (Thompson, 2012). In the year 2010, the demand for milk and milk products rose to 53.53 million litres per year, whereas the raw milk production from the national dairy herd was 7.71 million litres per year (SDB, 2011).Currently, the SDB has signed a memorandum of understanding with Swaziland Government to allow dairy farmers to source dairy cattle locally through the rehabilitation of the Gege ranch into a breeding station. Even though such a provision has been made, there are still numerous challenges in milk production in the country. These include high feed costs, livestock disease prevention and control costs. Milk production costs are higher compared to the revenue generated per litre of milk in Swaziland, which negatively affects the farmers' profit margins. Even though the market for milk is available in Swaziland, but the milk production rate is low, and that is attributed to the high production costs (Makhubu, 2012).

In spite of the efforts made by the Swaziland Government and Swaziland Dairy Board (SDB) in improving milk production in the country, smallholder dairy farmers still face high input costs in milk production coupled with the low milk price offered in the market, which together reduce their profit margins (Makhubu, 2012). This could be due to inefficiencies in the dairy industry. Dlamini (2012) found that smallholder dairy farmers in Swaziland are technically inefficient; however, there was need to investigate the economic efficiency of the smallholder dairy farmers. 
The main purpose of this study was to estimate the Economic Efficiency (EE) of smallholder dairy farmers in Swaziland. The specific objectives were to: describe the socioeconomic characteristics of smallholder dairy farmers; estimate the economic efficiency of smallholder dairy farmers; and to identify factors affecting the economic efficiency of smallholder dairy farmers. The study tested the following hypotheses:

1. $\mathrm{H}_{0}=$ Smallholder dairy farmers are economically inefficient

2. $\mathrm{H}_{0}=$ Institutional factors, socioeconomic and farm characteristics have no significant effect on the economic efficiency of smallholder dairy farmers

According to Mr. T. Mnisi, dairy extension officer, (personal communication, November $14^{\text {th }}$, 2013), there is a great potential for improved milk production by smallholder dairy farmers in Swaziland. However, milk production has not increased significantly in recent years; while on the other hand, the human population has continued to grow at an unprecedented rate, increasing the milk demand. The poor performance and the under development of the dairy sector can be attributed to inefficiency of the local smallholder dairy farmers, who constitute a larger percentage of the dairy sector. Therefore, there was need to assess the economic efficiency of smallholder dairy farmers. Hence, the findings of this study are important because they reveal some information to help smallholder dairy farmers and all stakeholders (such as, the Ministry of Agriculture, SDB and the milk processing plants) in the dairy industry to try and improve economic inefficiency.

\section{Theoretical Framework}

Efficiency is considered as one of the most important issues in agricultural production economics. It is measured by comparing the actually attained value of the objective function against what is attainable at the production frontier. The analysis of production and resource use in the smallholder dairy sector has more significance in agricultural policy frameworks that seek to increase local milk production by encouraging optimal resource utilization. Improving technical and allocative efficiency is an important factor of productivity growth in a developing country like Swaziland. Hassanpour (2012) stated that the analysis of technical and allocative efficiencies under the current technological change in agriculture helps policy makers to formulate adequate and appropriate, extension services, pricing, marketing, and credit, input distribution and land allocation policies.

\subsection{Technical Efficiency}

In economic theory, a production function is described in terms of maximum output that can be produced from a specified set of inputs, given the existing technology available to the farm (Battese et al., 1995). When the farm produces at the optimal production frontier, it is considered efficient. The most common assumption is that the goal of the producer is profit maximization; however, it is believed that the objectives and goals of the producer are intertwined with farmers' psychological make-up. Technical Efficiency (TE) is achieved when a high level of output is realized given a minimum level of inputs. It is therefore concerned with the efficiency of the input to output transformation. The reason for TE research is to understand factors that shift production function upwards on the production 
frontier (Battese et al., 1995).

\subsection{Allocative Efficiency}

Allocative efficiency (AE) is the ability of the firm to allocate an input bundle or produce a given level of output in the cost minimizing way (Chukwuji et al., 2006). Thus, the allocatively efficient level of production is where the farm operates at the least-cost combination of inputs. AE can also be defined as the ratio between total costs of producing a unit of output using actual factor proportions in a technically efficient manner, and total costs of producing a unit of output using optimal factor proportions in a technically efficient manner. Thus for the farm to maximize profit, under perfectly competitive markets, it is required that the extra revenue (Marginal Value Product) generated from the employment of an extra unit of a resource must be equal to its unit cost (Marginal Cost $=$ unit price of input) (Chukwuji et al., 2006).

\subsection{Economic Efficiency}

In microeconomic theory of the firm, $\mathrm{EE}$ is divided into TE and $\mathrm{AE}$. A producer is said to be technically efficient if production occurs on the boundary of the producer's production possibilities set. That means TE is the extent to which the maximum possible output is achieved from a given combination of inputs. On another note, a producer is said to be allocatively efficient if production occurs in a region of the production possibilities set that satisfies the producer's behavioral objective (Ellis, 1988; Snyder \& Nicholson, 2008). Farrell (1957) distinguished between technical and allocative efficiency in production through the use of a frontier production function. TE is the ability of a firm to produce a given output using the smallest set of inputs. It is attained when the best available technology is used to produce maximum output possible. AE is the ability of the firm to allocate an input bundle or produce a given level of output in the cost minimizing way. EE is the product of TE and AE. An economically efficient input-output combination would be on both the frontier function and the expansion path. Alternatively, EE can be defined as the ability of a firm to produce a given output at minimum cost. If a firm has achieved both technically efficient and allocatively efficient production levels, it is economically efficient (Farrell, 1957; Snyder \& Nicholson, 2008).

\subsection{Profit Maximization Theory}

The profit maximizing theory assumes that smallholder farmers are profit maximizing economic agents and are thus efficient producers. On the other hand, the risk-averse smallholder farmers' theory argues that poor smallholder farmers are risk-averse and they attempt to increase family security rather than maximizing profit (Mumba, 2012; Snyder \& Nicholson, 2008). In many industries, profit maximization is not simply a potential goal; it is the only feasible goal, given the desire of other business people to drive their competitors out of business (Skaggs, 2010). In economic terms, profit is the difference between a firm's total revenue and its total opportunity cost. Total revenue is the amount of income earned by selling products. Total opportunity cost includes both the costs of all inputs into the production process plus the value of the highest-valued alternatives to which owned resources could be put. 
Assuming that the overriding goal of the managers of firms is to maximize profit $(P=T R-T C)$, the managers maximize it by increasing total revenue (TR) or reducing total opportunity cost (TC) so that the difference rises to a maximum (Skaggs, 2010).

A firm can increase its output so long as the marginal revenue earned from additional units of production is greater than the marginal cost of those units. Marginal revenue is the additional revenue earned by selling one more unit of a product. Marginal cost is the additional cost incurred in producing one more unit of output. As long as MR > MC, profit grows. However, when $\mathrm{MR}<\mathrm{MC}$, profit shrinks. So firms expand output only to the point at which $\mathrm{MR}=\mathrm{MC}$, which is the point that maximizes profit. The profit-maximization rule applies both to firms that are able to sell their product at a constant price and to firms that find they must reduce the price of their product to increase sales. In the real world, firms have to engage in trial-and-error discovery processes, searching for the profit-maximization point. The process can be clearly described by the marginal revenue-marginal cost rule (Skaggs, 2010; Snyder \& Nicholson, 2008).

\section{Methodology}

Swaziland is comprised of four administrative regions, which are; Hhohho, Manzini, Lubombo and Shiselweni. This study was conducted in all the regions of the country.

\subsection{Research Design}

The study utilised a descriptive and quantitative research design to analyse the economic efficiency and profitability of smallholder dairy farming in Swaziland.

\subsection{Sampling Technique}

The target population was all the SDB registered smallholder dairy farmers in Swaziland. The total population was: $\mathrm{N}=444$ farmers (T. Mnisi, personal communication, November $11^{\text {th }}$, 2013). The purposive and random sampling techniques were used to select the respondents. The overall sample $(\mathrm{S})$ was $=111$ farmers. The formula for sample size determination by Bartlett, Kotrlik and Higgins (2001) was used to determine the sample size for each region. Table 1 shows the population and sample sizes from the different regions.

Table 1. Smallholder dairy farmers' sample size per region

\begin{tabular}{|l|c|c|}
\hline \multicolumn{1}{|c|}{ Region } & Population (N) & Sample (n) \\
\hline Manzini & 205 & 50 \\
Hhohho & 103 & 26 \\
Shiselweni & 82 & 21 \\
Lubombo & 54 & 14 \\
\hline Total & 444 & 111 \\
\hline
\end{tabular}

\subsection{Data Collection Instrument}

The research questionnaire was divided into three parts, which were according to the specific objectives. Part 1 was based on the factors affecting EE (farm characteristics, socioeconomic characteristics and institutional factors); part 2 was based on technical factors (general milk production) and part 3 was based on the costs and returns for the smallholder dairy enterprise. 
Closed-ended and open-ended questions were used in the questionnaire because of the nature of the data that was collected from the farmers. The instrument was reviewed for content validity by a panel of experts consisting of information officers in the SDB, Ministry of Agriculture and two experts from the Agricultural Economics and Management (AEM) Department of the Faculty of Agriculture. This was to ensure that the instrument measured what it intended to measure; items were clearly worded; and statements were not ambiguously stated. The corrections and suggestions from the experts were used to modify the items of the instrument. A pre-test was conducted with eight smallholder dairy farmers, in order to establish the reliability of the instrument.

\subsection{Data Collection}

Data were collected from primary data sources. Primary field surveys of sampled smallholder dairy farmers were conducted to gather information about the socioeconomic characteristics, dairy production, input and output levels, farm management practices as well as income received from the dairy farming through the use of a structured questionnaire.

\subsection{Data Analysis}

Data were analysed using the descriptive statistics, Cobb-Douglas regression analysis in the form of a profit function, and Tobit regression.

\subsection{Analytical Framework}

\subsubsection{Estimation of Economic Efficiency}

Economic efficiency was estimated using a Cobb Douglas Stochastic Profit Function. The Stochastic Profit Function approach combines the concepts of TE and AE in the profit relationship. So, the Profit Function was chosen over the Production Function because the production function requires that $\mathrm{TE}$ and $\mathrm{AE}$ be regressed separately in order to estimate $\mathrm{EE}$, while the profit function just analyses EE directly. The two stage approach of analyzing EE based on Stochastic Profit Frontier is as follows;

1. Estimate the stochastic profit function, from which efficiency scores are derived.

2. Efficiency scores are regressed on explanatory variables using Tobit regression.

This study assumed that the monthly profit obtained by each farmer from milk output was dependent on herd size, concentrate feed costs, labour costs, chemical costs, grazing pasture size and milk output per cow. Therefore, EE was estimated following monetary relationships derived from the Cobb Douglas profit function. The function was normalized by dividing both the dependent variable and the explanatory variables by the selling price of milk. The model used in this study was expressed in general form as:

$$
\pi=f\left(X_{1}, X_{2}, X_{3}, X_{4}, X_{5}, X_{6}\right)
$$

The empirical form of the model was expressed as:

$$
\pi=f\left(X_{\text {herd size }}, X_{\text {feedcosts }}, X_{\text {labourcosts }}, X_{\text {chemicalscosts }}, X_{\text {pasturesize }}, X_{\text {outputpercow }}\right)
$$

The normalized Cobb-Douglas stochastic profit function was specified as follows: 


$$
\pi=\beta_{0} X_{1}^{\beta 1} X_{2}^{\beta 2} X_{3}^{\beta 3} X_{4}^{\beta 4} X_{5}^{\beta 5} X_{6}^{\beta 6} e^{v-u}
$$

Taking the natural logarithms of both sides, the log linear form of the profit function used becomes:

$$
\ln \pi=\beta_{0}+\beta_{1} \ln X_{1}+\beta_{2} \ln X_{2}+\beta_{3} \ln X_{3}+\beta_{4} \ln X_{4}+\beta_{5} \ln X_{5}+\beta_{6} \ln X_{6}+\left(v_{i}-u_{i}\right)
$$

Where:

$\ln \pi=$ natural logarithm of the normalized monthly gross margin (Emalangeni)

$\ln X_{1}=$ natural logarithm of the herd size (total number of cows per farm) normalized by the price of milk

$\ln X_{2}=$ natural logarithm of the total cost of concentrate feed used in each farm (Emalangeni) normalized by the price of milk

$\ln X_{3}=$ natural logarithm of total labour costs (Emalangeni) normalized by the milk price

$\ln X_{4}=$ natural logarithm of total costs of chemicals (Emalangeni) normalized by the milk price

$\ln X_{5}=$ natural logarithm of grazing pasture size (hectares) normalized by milk price

$\ln X_{6}=$ natural logarithm of milk output per cow (litres) normalized by milk price

$\left(v_{i}-u_{i}\right)=e=$ random error term

$\beta_{0}, \beta_{1}, \beta_{2}, \beta_{3}$ and $\beta_{4}=$ are unknown parameters to be estimated

The error term, $e$, is composite (Ali \& Flin, 1989; Bravo-Ureta \& Pinheiro, 1991; and Saha et al, 2004).

$$
\text { Thus } e=\left(v_{i}-u_{i}\right)
$$

Where $v$ is a two-sided $(-\infty<v<\infty)$ normally distributed random error $\left[V \approx N\left(0, \sigma_{v}{ }^{2}\right)\right]$ that captures the stochastic effects outside the farmer's control (e.g., weather, natural disasters, and luck), measurement errors, and other statistical noise. The term $u$ is a one-sided $(u \geq 0)$ efficiency component that captures the economic inefficiency of the farmer. It measures the shortfall in profit $(\pi)$ from its maximum value given by the stochastic frontier $f\left(X_{i} ; \beta_{i}\right)+v$. We assume $u$ has an exponential distribution $\left[U \approx N\left(0, \sigma_{u}{ }^{2}\right)\right]$. The two components $v$ and $u$ are also assumed to be independent of each other. The parameters were estimated by the maximum likelihood method following Bravo-Ureta and Pinheiro (1993) and Bi (2004). Following Jondrow et al. (1982), the technical efficiency estimation is given by the mean of the conditional distribution of inefficiency term $U_{i}$ given $\varepsilon_{i}$; and thus defined by:

$$
E\left(U_{i} \mid \varepsilon_{i}\right)
$$

\subsubsection{Estimation of Factors Affecting Economic Efficiency}

To estimate the factors affecting EE, a Tobit regression model was used. The Tobit model was used because the efficiency scores lie within a double bounded range of 0 to 1 . The Tobit 
regression model coefficients do not directly give the marginal effects of the associated independent variables on the dependent variable. But their signs show the direction of change in the dependent variable as the respective explanatory variables change (Goodwin, 1992; Mussa, 2011). The Tobit regression model was estimated as;

$$
\begin{gathered}
Y_{i}^{*}=\beta_{0}+\beta_{1} X_{1}+\beta_{2} X_{2}+\beta_{3} X_{3}+\beta_{4} X_{4}+\beta_{5} X_{5}+\beta_{6} X_{6}+\beta_{7} X_{7}+\beta_{8} X_{8}+\beta_{9} X_{9}+\beta_{10} X_{10}+\beta_{11} X_{11}+ \\
\beta_{12} X_{12}+\beta_{13} X_{13}
\end{gathered}
$$

Where $Y^{*}=$ level of EE; $X_{i}$ is a vector of explanatory variables that include age (in years), gender ( $1=$ male; $0=$ female), education level (in years of study), household size (number), years of experience for the household head (in years), farm location ( $1=\mathrm{SNL}$; $0=\mathrm{TDL}$ ), water availability $(1=$ yes; $0=$ no), pasture size (hectares), soil fertility $(1=\operatorname{good} ; 0=$ poor $)$, membership to dairy farmers association $(1=$ yes; $0=$ no), training on dairy farming $(1=$ yes; 0 $=$ no) and distance travelled to the market (in kilometres), herd size (total number).

Table 2. Two-limit Tobit Regression Model Variables

\begin{tabular}{|l|l|l|c|}
\hline \multicolumn{1}{|c|}{$\begin{array}{c}\text { Explanatory } \\
\text { Variables }\end{array}$} & \multicolumn{1}{|c|}{ Description of Variables } & \multicolumn{1}{c|}{$\begin{array}{c}\text { Unit of } \\
\text { Measurement }\end{array}$} & $\begin{array}{c}\text { Hypothesized } \\
\text { Sign }\end{array}$ \\
\hline Age-X1 & Age & Years & + \\
Gender-X2 & Gender & 1= male; $0=$ female & $-/+$ \\
Ed.Level-X3 & Educational level & Years & + \\
Hsholdsz-X4 & Household size & Number & + \\
Exper-X5 & Farmer's experience & Years & + \\
Fmloc-X6 & Farm location & $1=$ SNL; $0=$ TDL & $-/+$ \\
Wtav-X7 & Water availability & $1=$ yes; $0=$ no & $-/+$ \\
Pastsize-X8 & Pasture size & Hectares & + \\
Soilfert-X9 & Soil fertility & $1=$ good; $0=$ poor & $-/+$ \\
Mdfa-X10 & Membership to a dairy farmers & & \\
& association & $1=$ yes; $0=$ no & $-/+$ \\
Train.-X11 & Training 2 years ago & $1=$ yes; $0=$ no & $-/+$ \\
Dist.-X12 & Distance to market & Kilometres & - \\
Hdsze-X13 & Herd size & Total number & + \\
\hline
\end{tabular}

\section{Results and Discussion}

\subsection{Description of Smallholder Dairy Farmers and Their Farms}

Table 3 presents the socioeconomic characteristics of smallholder dairy farmers. The results of the study indicated that $33 \%$ of the sampled smallholder dairy farmers were females, while $67 \%$ were males. This was an indication that the dairy farming was dominated by male farmers in Swaziland. The age of the sampled smallholder dairy farmers ranged from 31 to 75 years old. The majority (32\%) of the farmers had their age ranging from 51 to 60 years. The mean age was 55 years. The results also indicated that $78 \%$ of the sampled smallholder dairy farmers attained tertiary education. This means education enlightened the farmers about risks and uncertainty involved in the dairy business, and it also sharpened their problem solving abilities. It was also revealed that $89 \%$ of the sampled smallholder dairy farmers were married. The findings of the study also indicated that $68 \%$ of the farmers had household sizes ranging from 4 to 8 members. 


\section{Macrothink}

The results further showed that $37 \%$ of the farmers had a dairy farming experience ranging from 11 to 15 years. The average experience of farmers in dairy farming was 11.14 years. The results also revealed that $98 \%$ of the dairy farmers had an off-farm income. This implied that very few farmers were solely depending on dairy farming for their livelihoods, most farmers had other sources of income.

The results showed that $29 \%$ of the dairy farmers had pastures with sizes ranging from 2 to 2.9 hectares. However, the mean pasture size was 6 hectares. The results also showed that $76 \%$ of the dairy farmers tested their pasture soils, as a result of knowing the conditions of their soils; they were able to maintain good soil fertility. A majority (96\%) of the smallholder dairy farms was located on the Swazi Nation Land, while the remaining $4 \%$ were located on the Title Deed Land. The findings also revealed that $76 \%$ of the smallholder dairy farms had available water for the irrigation of the pastures, while the remaining $24 \%$ had no water available for pasture irrigation. It was expected for dairy farmers in farms with available water for pasture irrigation to have better efficiency.

Table 3. Farm and socioeconomic characteristics for smallholder dairy farmers

\begin{tabular}{|c|c|c|c|c|}
\hline \multirow{2}{*}{\multicolumn{5}{|c|}{\begin{tabular}{|l|l|l|} 
Frequency & Percentage & Mean \\
\end{tabular}}} \\
\hline & & & & \\
\hline Female & 37 & 33.3 & & \\
\hline Male & 74 & 66.7 & & \\
\hline Total & 111 & 100.00 & & \\
\hline \multicolumn{5}{|l|}{ Farmer's age } \\
\hline $31-40$ & 7 & 6.31 & & \\
\hline $41-50$ & 33 & 29.73 & & \\
\hline $51-60$ & 35 & 31.53 & & \\
\hline $61-70$ & 32 & 28.83 & & \\
\hline $71-75$ & 4 & 3.60 & & \\
\hline Total & 111 & 100.00 & 54.802 & 9.449 \\
\hline \multicolumn{5}{|l|}{ Level of education } \\
\hline None & 1 & 0.90 & & \\
\hline Primary & 5 & 4.50 & & \\
\hline Junior & 10 & 9.01 & & \\
\hline High school & 8 & 7.21 & & \\
\hline Tertiary & 87 & 78.38 & & \\
\hline Total & 111 & 100.00 & & \\
\hline \multicolumn{5}{|l|}{ Marital Status } \\
\hline Single & 1 & 0.90 & & \\
\hline Married & 99 & 89.19 & & \\
\hline Widowed & 8 & 7.21 & & \\
\hline Separated & 3 & 2.70 & & \\
\hline Total & 111 & 100.00 & & \\
\hline \multicolumn{5}{|l|}{ Household size } \\
\hline $1-3$ & 11 & 9.9 & & \\
\hline $4-8$ & 75 & 67.57 & & \\
\hline $9-13$ & 20 & 18.02 & & \\
\hline $14-35$ & 5 & 4.50 & & \\
\hline Total & 111 & 100.00 & 6.847 & 4.185 \\
\hline \multicolumn{5}{|l|}{ Dairy farming experience } \\
\hline $1-5$ & 14 & 12.61 & & \\
\hline $6-10$ & 37 & 33.33 & & \\
\hline $11-15$ & 41 & 36.94 & & \\
\hline $16-20$ & 15 & 13.51 & & \\
\hline $21-36$ & 4 & 3.60 & & \\
\hline Total & 111 & 100.00 & 11.144 & 5.164 \\
\hline
\end{tabular}




\begin{tabular}{|c|l|l|l|l|}
\hline Off-farm income & & & & \\
No & 2 & 1.80 & & \\
Yes & 109 & 98.20 & & \\
Total & 111 & 100.00 & & \\
Pasture size (Ha) & & & & \\
$0.1-0.9$ & 13 & 11.7 & & \\
$1.0-1.9$ & 18 & 16.2 & & \\
$2.0-2.9$ & 32 & 28.8 & & \\
$3.0-3.9$ & 17 & 15.3 & & \\
$4.0-4.9$ & 11 & 9.9 & & \\
$5.0-6.9$ & 11 & 9.9 & & \\
$7.0-200$ & 9 & 8.2 & & \\
Total & 111 & 100 & 5.777 & 20.02 \\
\hline
\end{tabular}

\subsection{Profitability Estimates}

The estimation of the Cobb-Douglas Stochastic Profit Frontier Function generated the results for the maximum likelihood estimates (MLE) presented in Table 4. The coefficients of the explanatory variables, herd size $\left(\mathrm{X}_{1}\right)$, feed costs $\left(\mathrm{X}_{2}\right)$, chemical costs $\left(\mathrm{X}_{4}\right)$, pasture size $\left(\mathrm{X}_{5}\right)$ and output per cow $\left(\mathrm{X}_{6}\right)$ had positive signs, while the labour costs $\left(\mathrm{X}_{3}\right)$ had a negative sign. This meant that $1 \%$ increase in herd size, concentrate feed expenditure, chemicals expenditure, pasture size, milk output per cow would increase monthly profit by $1.6 \%, 0.3 \%, 1.8 \%, 0.2 \%$ and $1.7 \%$ respectively. On the contrary, $1 \%$ increase in labour costs would reduce the monthly profit by $0.7 \%$. Chemical costs $\left(\beta_{4}\right)$ were significant at $1 \%$ level of significance; herd size $\left(\beta_{1}\right)$, pasture size $\left(\beta_{5}\right)$ and the output per cow $\left(\beta_{6}\right)$ were significant at $5 \%$ level of significance; and the feed costs $\left(\beta_{2}\right)$ were significant at $10 \%$ level of significance The findings were in line with the results of a study by Herero et al. (2010), which revealed that factors that significantly affect EE of dairy farmers included cattle feed, chemicals, herd size and pasture size. It was also found that efficiency levels were positively related to pasture size allocated per cow and amount of concentrate feed rationed per cow (Kinambuga, 2010).

Table 4. Maximum likelihoods for profitability estimates

\begin{tabular}{|l|c|c|c|c|}
\hline Profitability factors & Coefficient & Standard error & z-value & p-value \\
\hline lnHerd size & $1.556^{* *}$ & 0.090 & 1.15 & 0.048 \\
lnFeed costs & $0.342^{*}$ & 0.092 & 1.68 & 0.093 \\
lnLabour costs & -0.690 & 0.538 & -1.28 & 0.200 \\
lnChemical costs & $1.832^{* * *}$ & 0.662 & 2.77 & 0.006 \\
lnpasture size & $0.183^{* *}$ & 0.416 & 1.26 & 0.039 \\
lnMilk per cow & $1.731^{* *}$ & 0.823 & 1.41 & 0.021 \\
Constant & -0.821 & 2.440 & -0.34 & 0.737 \\
\hline Sigma v & 0.715 & 0.368 & & \\
Sigma u & 0.868 & 0.872 & & \\
Lambda & 1.215 & 1.216 & & \\
\hline
\end{tabular}

$* * *=1 \%$ significance level $; * *=5 \%$ significance level $; *=10 \%$ significance level

\subsection{Economic Efficiency of Smallholder Dairy Farmers}

With reference to Table 5, the results of the study indicated an average EE level of $77.4 \%$ in the Manzini region; $86.7 \%$ in the Shiselweni region; $79.7 \%$ in the Hhohho region and $75.1 \%$ in the 
Lubombo region. The overall mean level of EE for smallholder dairy farmers was found to be $79.8 \%$ suggesting that a majority of the sampled smallholder dairy farmers were economically efficient, and there was a potential for smallholder dairy farmers to increase their EE by $20.2 \%$.

Table 5. Economic Efficiency of smallholder dairy farmers by regions

\begin{tabular}{|l|c|c|c|c|}
\hline \multicolumn{1}{|c|}{ Region } & Mean EE & $\begin{array}{c}\text { Standard } \\
\text { deviation }\end{array}$ & Minimum & Maximum \\
\hline Manzini & 0.774 & 0.207 & 0.493 & 0.923 \\
Shiselweni & 0.867 & 0.109 & 0.774 & 0.860 \\
Hhohho & 0.797 & 0.215 & 0.381 & 0.820 \\
Lubombo & 0.751 & 0.074 & 0.667 & 0.804 \\
Overall & 0.798 & 0.179 & 0.381 & 0.923 \\
\hline
\end{tabular}

4.3.1 Frequency distribution for economic efficiency of dairy farmers

The results of the study indicated that $12.6 \%$ of the farmers achieved EE of less than $50 \%$; $16.2 \%$ of the farmers attained EE ranging from $50 \%$ to $59 \% ; 23.4 \%$ of the farmers attained EE ranging from $60 \%$ to $69 \%$; $34.2 \%$ of the farmers attained EE ranging from $70 \%$ to $79 \%$; and $13.6 \%$ of the farmers attained EE ranging from $80 \%$ to $99 \%$. The minimum EE was $38.1 \%$, the maximum EE was $92.3 \%$ and the average EE was $79.8 \%$.

Table 6. Frequency distribution of the farmers' Economic Efficiency

\begin{tabular}{|c|c|c|}
\hline EE (\%) & Frequency & Percentage \\
\hline $30-39$ & 3 & 2.7 \\
$40-49$ & 11 & 9.9 \\
$50-59$ & 18 & 16.2 \\
$60-69$ & 26 & 23.4 \\
$70-79$ & 38 & 34.2 \\
$80-89$ & 13 & 11.7 \\
$90-99$ & 2 & 1.9 \\
Total & 111 & 100 \\
Average EE $=79.8 \%$ & & \\
Minimum EE $=38.1 \%$ & & \\
Maximum EE $=92.3 \%$ & & \\
\hline
\end{tabular}

\subsection{Factors Affecting Economic Efficiency}

Table 7 presents the results of the factors affecting the level of EE for smallholder dairy farmers in Swaziland. The coefficients of the explanatory variables; availability of water for pasture irrigation, pasture size, soil fertility, dairy farming experience, membership to a dairy farmers association, training on dairy farming, and herd size had positive signs. Water availability for pasture irrigation was significant at $1 \%$ level; the location of the farm, soil fertility, farmer's experience in dairy farming, membership to dairy farmers' association, and training were significant at 5\% level; pasture size and herd size were significant at $10 \%$ level. This suggested that a 1litre increase in water available for pasture irrigation would increase the level of EE by 0.18 ; an increase in pasture size by $1 \mathrm{~m}^{2}$ would increase the level of EE by 0.06 ; a unit increase in the fertility of the pasture's soil would increase the level of EE by 0.05 ; a 10 years increase in the dairy farming experience would improve EE by 0.03 , while; a year's increase in the farmer's membership period in a dairy farmers' association would increase the EE level by 0.12; a frequency increase in dairy farming training increased EE level by the value of 0.08; 
and an increase of herd size by 1cow, would increase EE by 0.032 .

Table 7. Factors affecting Economic Efficiency of Smallholder Dairy Farmers

\begin{tabular}{|l|c|c|c|c|}
\hline \multicolumn{1}{|c|}{ EE Factors } & Coefficient & Standard Error & t-value & p-value \\
\hline Location & $-0.260^{* *}$ & 0.089 & -2.93 & 0.012 \\
Water for irrigation & $0.184^{* *}$ & 0.057 & 3.25 & 0.007 \\
Pasture size & $0.064 *$ & 0.045 & 1.83 & 0.085 \\
Soil fertility & $0.045^{* *}$ & 0.065 & 2.02 & 0.032 \\
Gender & -0.050 & 0.046 & -1.08 & 0.298 \\
Age & 0.006 & 0.004 & 1.65 & 0.100 \\
Level of education & -0.055 & 0.051 & -1.07 & 0.297 \\
Household size & 0.011 & 0.014 & 0.60 & 0.561 \\
Dairy experience & $0.003 * *$ & 0.006 & -2.57 & 0.041 \\
Assoc. membership & $0.118^{* *}$ & 0.055 & 2.16 & 0.049 \\
Training & $0.077 * *$ & 0.114 & -0.68 & 0.037 \\
Distance to market & 0.004 & 0.004 & 1.10 & 0.289 \\
Herd size & $0.032^{*}$ & 0.017 & 0.27 & 0.089 \\
Constant & $0.813^{* * *}$ & 0.265 & 3.07 & 0.009 \\
\hline Sigma & 0.086 & 0.013 & & \\
\hline
\end{tabular}

$*=$ significant at $10 \%$ level; $* *=$ significant at $5 \%$ level; $* * *=$ significant at $1 \%$

\subsection{Decision Regarding Major Hypothesis}

The overall average EE level for smallholder dairy farmers was $79.8 \%$, meaning that the smallholder dairy farmers were economically efficient. Therefore, the null hypothesis $\left(\mathrm{H}_{0}=\right.$ smallholder dairy farmers are economically inefficient) was rejected in favour of the alternative hypothesis $\left(\mathrm{H}_{1}=\right.$ smallholder dairy farmers are economically efficient). The variables: farm location, availability of water for the pasture's irrigation, pasture size, pasture's soil fertility, the dairy farming experience, membership to a dairy farmers' association, training on dairy farming, and herd size contribute to the explanation of the variations in EE of the dairy farmers. Therefore, the null hypothesis $\left(\mathrm{H}_{0}=\right.$ institutional factors, socioeconomic and farm characteristics have insignificant effects on the level of EE) was rejected in favour of the alternative hypothesis $\left(\mathrm{H}_{1}=\right.$ institutional factors, socioeconomic and farm characteristics have significant effects on the level of EE).

\section{Conclusions and Recommendations}

\subsection{Conclusions}

The findings of the study indicated an average of $79.8 \%$ level of EE for smallholder dairy farmers in Swaziland. Therefore, there is a $20.2 \%$ potential for smallholder dairy farmers to increase their EE. Hence, the null hypothesis $\left(\mathrm{H}_{0}=\right.$ smallholder dairy farmers are economically inefficient $)$ was rejected and the alternative hypothesis $\left(\mathrm{H}_{1}=\right.$ smallholder dairy farmers are economically efficient) was accepted. The farm's location, pasture size, soil fertility, water availability for the irrigation of the pasture, the farmer's years of experience in dairy farming, membership to dairy farmers' association, training on dairy farming, and herd size are factors that influenced the level of EE for smallholder dairy farmers in Swaziland. Therefore, the null hypothesis $\left(\mathrm{H}_{0}=\right.$ institutional factors, socioeconomic and farm characteristics no significant effect on the level of EE among smallholder dairy farmers) was rejected, and the alternative 
hypothesis $\left(\mathrm{H}_{1}=\right.$ institutional factors, socioeconomic and farm characteristics have a significant effect on the level of EE among smallholder dairy farmers) was accepted.

The findings of this study were in line with results for a study by Herero et al. (2010), which revealed that factors that significantly affect EE of dairy farmers include cattle feed, chemicals, herd size and pasture size. The results further collaborated with those of Kinambuga (2006), which indicated that efficiency levels were positively related to pasture size allocated per cow and amount of concentrate feed rationed per cow. The results were also in line with those of Mumba (2012), which revealed several socioeconomic characteristics of smallholder dairy farmers such as, income from off-farm jobs, availability of capital, milk prices, price of land, farmer education and training, and availability of family labour, influence a dairy farmers' decision on whether to expand and improve dairy operations. The results of this study revealed that the farmer's age had no significant effect to EE and profitability, which was similar to Mumba (2012), who found that age had no significant effect on the profitability of smallholder dairy enterprise.

\subsection{Recommendations}

Based on the results, the study recommends that since the herd size, concentrate feed, and chemical costs, pasture size and milk output per cow, were positively related with the monthly profit, it is recommended that smallholder dairy farmers increase these inputs possibly with assistance from the government to maximize profit. Labour costs had an inverse relationship with the monthly profit, so it is recommended that smallholder dairy farmers should reduce labour in the farm in order to improve economic efficiency. The membership to a dairy farmers' association had a positive relationship with the level of EE, so it is recommended that smallholder dairy farmers join these associations in order to share information and skills, which can eventually improve their EE. Some of the smallholder dairy farmers were not trained on dairy farming as a business, yet the study results revealed that training has positive effects on the level EE of dairy farmers. Therefore, it is recommended that SDB conducts its trainings even in the other regions of the country, since currently they are conducted only in Manzini.

\section{References}

Ali, M., \& Flinn, J. C. (1989). Profit Efficiency among Basmati Rice Producers in Pakistan's Punjab. American Journal of Agricultural Economics, 17, 303-310. http://dx.doi.org/10.2307/1241587

Battese, G. E., \& Coelli, T. J. (1995). A Model of Technical Inefficiency Effects in a Stochastic Frontier Function for Panel Data. Empirical Economics, 20, 325-332. http://dx.doi.org/10.1007/BF01205442

Bravo-Ureta, B. E., \& Rieger, L. (1991). Dairy Farm Efficiency Measurement Using Stochastic Frontiers and Neoclassical Duality. American Journal of Agricultural Economics, 73, 421-428. http://dx.doi.org/10.2307/1242726

CBS (2010). Annual Report for 2009/2010. Central Bank of Swaziland, Mbabane, Swaziland. Chukwuji, C., Odjuvwuederhie, O., Inoni, E., O’raye, S., Ogisi, D., William, H., \& Oyaide J. 
(2006). A Quantitative Determination of Allocative Efficiency in Broiler Production in Delta State, Nigeria. Agriculturae Conspectus Scientifi cus, 71(1), 21-26.

Dlamini, Z. (2012). Technical efficiency for smallholder dairy farmers in Swaziland. Unpublished M.Sc. thesis. University of Swaziland, Luyengo.

Ellis, F. (1988). Peasant Economics: Farm Households and Agrarian Development. Cambridge University Press. Cambridge. United Kingdom.

Farrell, M. J. (1957). Measurement of Productive Efficiency. Journal of Royal Statistics Society, Series A, 120, 253-290. http://dx.doi.org/10.2307/2343100

Goodwin, B. K. (1992). An analysis of factors associated with consumers' use of grocery coupons. Journal of Agricultural and Resource Economics, 17, 110-120.

Hassanpour, B. (2012). Factors Affecting Economic Efficiency of Sheep Fattening Industries in Fars Province, Iran. Annals of Biological Research, 3, 5296-5303.

Herrero, M., Nganga, S. K., Kungu, J., \& de Ridder, N. (2010). Profit efficiency among Kenyan smallholder milkproducers: A case study of Meru-South district,Kenya. African Journal of Agricultural Research, 5(4), 332-337.

Kinambuga, D. (2010). Evaluation of the constraints to profitable smallholder dairying: A case of Nakuru County, Kenya. Unpublished M.Sc. Thesis.Egerton University.

Makhubu, S. (2012, November $7^{\text {th }}$ ) Breeding dairy cattle in Swaziland. The Times of Swaziland. p.14.

Mburu, L. M., Gitu, K. W., \& Wakhungu, J. W. (2007). A cost-benefit analysis of smallholder dairy cattle enterprises in different agro-ecological zones in Kenya highlands. Livestock Research for Rural Development, 19(2), 23 - 32.

Mumba, C. (2012). Economic Analysis of the Viability of the Smallholder Dairy Farming in Zambia. Unpublished M.Sc. thesis. University of Zambia, School of Veterinary Medicine, Department of Disease Control, Lusaka.

Mussa, E. (2011). Economic Efficiency of Smallholder Major Crops Production in the Central Highlands of Ethiopia. Unpublished M.Sc. thesis. Egerton University, Kenya.

Saha, A., Garcia, O., \& Hemme, T.(2004).The economics of milk production in Odrissa, India with particular emphasis on small scale producers. Journal for International Farm Comparison Network, 3(2), 141-283.

SDB (2010). Annual Report 2009/2010. Swaziland Dairy Development Board, Manzini Swaziland. http://www.ciwf.org.uk. 8/3/2013.

SDB (2011). Annual Report 2010/2011. Swaziland Dairy Board, Manzini. Swaziland.

Simelane, N. (2011). An Assessment of the role of cooperatives in smallholder dairy production and marketing in Swaziland.Unpublished M.Sc. Thesis.University of Pretoria. http://upetd.up.ac.za. 17/6/2013. 


\section{Macrothink}

Journal of Agricultural Studies

ISSN 2166-0379 2014, Vol. 2, No. 2

Simwaka, K., Ferrer, S., \& Harris G. (2013). Analysis of factors affecting technical efficiency of smallholder farmers: Comparing time-varying and time-invariant inefficiency models. African Journal of Agricultural Research, 8(29), 3983 - 3993.

Snyder, C., \& Nicholson, W. (2008). Microeconomic Theory Tenth Edition. South-Western Cengage Learning, Natorp Boulevard, Mason, USA.

Staal, S. J., Baltenweck, I., Njoroge, L., Patil, B. R., Ibrahim, M. N. M, \& Kariuki, E. (2006). Smallholder Dairy Farmer Access to Alternative Milk Market Channels in Gujarat. International Livestock Research Institute, Nairobi, Kenya. Contributed Paper IAAE Conference, Brisbane, Australia.

Thompson, C. F. (2012). Business Yearbook. http://www.swazibusiness.com 14/6/2013.

\section{Copyright Disclaimer}

Copyright for this article is retained by the author(s), with first publication rights granted to the journal.

This is an open-access article distributed under the terms and conditions of the Creative Commons Attribution license (http://creativecommons.org/licenses/by/3.0/). 